\title{
Intoxicação experimental por Trema micrantha (Cannabaceae) em equinos ${ }^{1}$
}

\author{
Paulo M. Bandarra², Pedro S. Bezerra Júnior ${ }^{3}$, Luiz Gustavo S. de Oliveira², Gabriel \\ L.F. Correa ${ }^{2}$, Mauro R. Borba², José Reck Júnior ${ }^{4}$, Cláudio Estevão Farias da Cruz ${ }^{2}$ \\ e David Driemeier ${ }^{2 *}$
}

\begin{abstract}
Bandarra P.M., Bezerra Júnior P.S., Oliveira L.G.S., Correa G.L.F., Borba M.R., Reck Júnior J., Cruz C.E.F. \& Driemeier D. 2011. [Experimental Trema micrantha (Cannabaceae) poisoning in horses.] Intoxicação experimental por Trema micrantha (Cannabaceae) em equinos. Pesquisa Veterinária Brasileira 31(11):991-996. Setor de Patologia Veterinária, Faculdade de Veterinária, Universidade Federal do Rio Grande do Sul, Av. Bento Gonçalves 9090, Porto Alegre, RS 91540-000, Brazil. E-mail: davetpat@ufrgs.br

The aim of this study was to confirm the toxicity and characterize the clinical and pathological aspects of poisoning by Trema micrantha in horses. The green leaves of the plant were spontaneously consumed by three ponies at single doses of 20,25 , and $30 \mathrm{~g} / \mathrm{kg}$. The three ponies developed clinical disease characterized by apathy, equilibrium deficit, deglutition difficulty, sternal or lateral recumbency, paddling, coma and death. Affected ponies had also enhanced seric activity of gamma-glutamyl transferase, seric ammonia apart of diminished glycemia. An additional pony, that received 15 and $25 \mathrm{~g} / \mathrm{kg}$ of T. micrantha with a 30 day interval between the two doses, showed no clinical disease. The three ponies were necropsied and fragments from organs were collected for histology and immunostaining (IS) procedures. The main pathological findings were in the liver and encephalon. There were enhanced lobular pattern of the liver and yellowish areas in the cut surface of the encephalon, especially visualized in the cerebellar white matter. Microscopically, there was hepatocellular swelling and coagulative hepatic necrosis predominantly centrilobular with hemorrhages. Generalized perivascular edema and Alzheimer type II astrocytes were observed in the encephalon. The Alzheimer type II astrocytes showed weak or absent anti-glial fibrillar acid protein IS associated with positive IS for S-100 protein. The minimal lethal dose of Trema micrantha leaves was established at $20 \mathrm{~g} / \mathrm{kg}$. The sensibility of horses to this plant, its wide distribution and high palatability reinforces the importance of Trema micrantha in accidental poisoning of horses.
\end{abstract}

INDEX TERMS: Poisonous plants, Trema micrantha, Cannabaceae, liver necrosis, hepatic encephalopathy, plant poisoning, horses.

RESUMO.- 0 objetivo desse estudo foi confirmar a toxidez e caracterizar os aspectos clínicos e patológicos da intoxicação por Trema micrantha em equinos. Três equinos, pôneis,

\footnotetext{
${ }^{1}$ Recebido em 9 de agosto de 2011.

Aceito para publicação em 29 de agosto de 2011.

${ }^{2}$ Departamento de Patologia Clínica Veterinária, Faculdade de Veterinária, Universidade Federal do Rio Grande do Sul (UFRGS), Av. Bento Gonçalves 9090, Porto Alegre, RS 95320-000, Brasil. *Autor para correspondência: davetpat@ufrgs.br

${ }^{3}$ Setor de Patologia Veterinária, Departamento de Medicina Veterinária, Universidade Federal de Lavras (UFLA), Cx. Postal 3037, Lavras, MG 37200-000, Brasil.

${ }^{4}$ Centro de Biotecnologia, Universidade Federal do Rio Grande do Sul (UFRGS), Cx. Postal 15005, Porto Alegre, RS 91501-970, Brasil.
}

com idade entre 2 e 7 anos consumiram espontaneamente folhas de T. micrantha em doses únicas de $30 \mathrm{~g} / \mathrm{kg}, 25 \mathrm{~g} /$ $\mathrm{kg}$ e $20 \mathrm{~g} / \mathrm{kg}$. Os três animais adoeceram e evoluíram para morte. Outro equino recebeu 15 e $25 \mathrm{~g} / \mathrm{kg}$ da planta com intervalo de 30 dias entre as doses e não apresentou alteração clínica. Coletas diárias de sangue foram realizadas para análises bioquímicas. Os principais sinais clínicos apresentados foram apatia, desequilíbrios, dificuldade de deglutição, decúbito esternal, decúbito lateral, movimentos de pedalagem, coma e morte. Os três equinos afetados apresentaram elevação da atividade sérica de gama-glutamil transferase, dos níveis séricos de amônia e diminuição da glicemia. Esses animais foram necropsiados e fragmentos 
de diversos órgãos foram coletados para análise histopatológica e imuno-histoquímica. Os principais achados patológicos foram encontrados no fígado e no encéfalo dos três animais. 0 fígado apresentava, macroscopicamente, acentuação do padrão lobular; enquanto que, no encéfalo havia áreas amareladas na superfície de corte, mais evidentes na substância branca do cerebelo. Microscopicamente, o fígado apresentava tumefação hepatocelular, necrose de coagulação predominantemente centrolobular e hemorragia associada. No encéfalo, havia edema perivascular generalizado e astrócitos Alzheimer tipo II na substância cinzenta. Esses astrócitos apresentaram marcação fraca ou negativa na imuno-histoquímica anti-GFAP e marcação positiva do antígeno S-100. A dose letal mínima de folhas de T. micrantha estabelecida nesse experimento foi de $20 \mathrm{~g} / \mathrm{kg}$. A ampla distribuição e palatabilidade desta planta, associadas à alta sensibilidade da espécie equina, constatada nesse experimento, reforçam a importância da planta em casos acidentais de intoxicação em equinos.

TERMOS DE INDEXAÇÃO: Plantas tóxicas,Trema micrantha, necrose hepática, encefalopatia hepática, intoxicação por plantas, equinos.

\section{INTRODUÇÃO}

Trema micrantha (fam. Cannabaceae), conhecida popularmente como grandiúva, pau-pólvora e periquiteira (Lorenzi 2008), é uma espécie arbórea de crescimento rápido que atinge 5 a 15 metros de altura. Ocorre em grande parte da América do Sul, sendo também encontrada nas Américas Central e do Norte. No Brasil, está amplamente distribuída em formações florestais e como vegetação secundária em terrenos abandonados (Pio-Correa 1984, Vasquez 1998, Kissmann 2000). É utilizada como espécie pioneira em sistemas de reflorestamento e recuperação de solos degradados (Castellani \& Aguiar 1998). Seus frutos são avidamente consumidos por diversas espécies de pássaros (Lorenzi 2008). As folhas são palatáveis e prontamente consumidas pelos bovinos e outras espécies herbívoras, especialmente em épocas de escassez de alimento (Kissmann 2000). Intoxicações naturais por T. micrantha foram observadas em caprinos que eram mantidos estabulados, cujas folhas foram fornecidas no cocho para os animais (Traverso et al. 2003) e em outra propriedade onde a planta foi consumida após a queda de uma árvore (Traverso et al. 2005). Em equinos, a intoxicação natural foi observada no Rio Grande do Sul, em uma propriedade após consumo acidental de uma árvore derrubada por um temporal (Bandarra et al. 2010) e em outra propriedade onde uma árvore foi podada e os equinos tiveram acesso aos galhos (Bandarra, dados não publicados). A intoxicação foi induzida experimentalmente em bovinos (Traverso et al. 2004), caprinos (Traverso et al. 2002) e coelhos (Traverso \& Driemeier 2000) em doses de 50,30 e $35 \mathrm{~g} / \mathrm{kg}$, respectivamente. Na Austrália, Trema tomentosa, na qual foi demonstrada a presença de um glicosídio tóxico denominado trematoxina (Oelrichs 1968), tem sido associada com intoxicações em equinos (Hill et al. 1985) e outras espécies animais (Mulhearn 1942, Mckenzie et al. 1985, Trueman \& Powell 1991). 0 quadro clínico-patológico observado na intoxicação por plantas do gênero Trema é de insuficiência hepática aguda por necrose hepatocelular (Traverso et al. 2003, 2004). 0 objetivo desse trabalho foi determinar a toxidez das folhas de $T$. micrantha para a espécie equina, assim como estabelecer a dose tóxica, o quadro clínico-patológico e as alterações bioquímicas nessa espécie animal.

\section{MATERIAL E MÉTODOS}

Nesse trabalho experimental foram utilizados quatro equijos, pôneis, sem raça definida, com idade entre 2 e 7 anos. Todos os equinos foram pesados antes do início do estudo. Os animais eram mantidos em baias individuais de alvenaria, com piso de cimento e cama de maravalha. A alimentação era constituída de feno de alfafa, ração comercial própria para equinos e água ad libitum. As folhas de Trema micrantha foram coletadas no Município de Porto Alegre e fornecidas no mesmo dia da coleta. Os animais consumiram espontaneamente a dose fornecida em um período inferior a 24 horas. A dose fornecida inicialmente a um equino (Equino 1) foi de $30 \mathrm{~g} / \mathrm{kg}$ de peso vivo, baseada na dose tóxica observada em caprinos (Traverso et al. 2002). Após, foram fornecidas doses decrescentes de 25g/kg (Equino 2), 20g/ kg (Equino3) e $15 \mathrm{~g} / \mathrm{kg}$ (Equino 4). Ao Equino 4, que recebeu uma dose de $15 \mathrm{~g} / \mathrm{kg}$, foi fornecida uma dose adicional de $25 \mathrm{~g} / \mathrm{kg}, 30$ dias após o consumo da primeira dose. Os animais foram submetidos a exames clínicos diários e amostras de sangue foram coletadas diariamente em tubos sem anticoagulante para avaliação da atividade sérica de gama glutamil transferase (GGT) e dos níveis séricos de amônia. Amostras de sangue também foram coletadas em tubos com fluoreto de sódio para determinação da glicemia. A determinação da atividade sérica de GGT foi realizada através de ensaio automatizado em espectrofotômetro de microplacas (SpectraMax, Molecular Devices Co., Sunnyvale, CA, EUA), utilizando o kit $\gamma$-GT (Doles Reagentes, Goiânia, GO, Brasil) baseado no método de Naftalin modificado (Naftalin et al. 1969). Os níveis de glicose foram determinados em amostras de plasma obtido por centrifugação (2500rpm/10min.) do sangue coletado em fluoreto de sódio. A dosagem de glicose foi realizada através de ensaio automatizado em espectrofotômetro de microplacas, utilizando o kit Glicose Enzimática Liq (Doles Reagentes, Goiânia, GO, Brasil) baseado no método de glicose oxidase (Trinder 1969). Os níveis de amônia sérica foram quantificados através de ensaio automatizado em espectrofotômetro de microplacas, de acordo com protocolo estabelecido por Verdouw e colaboradores (1978), baseado no método do indofenol. Os valores de GGT, glicose e amônia foram expressos como a média de quatro replicatas técnicas. Os Equinos 1, 2 e 3 foram necropsiados logo após a morte e fragmentos de diversos órgãos foram coletados em formalina tamponada 10\%, processados conforme métodos histológicos de rotina e corados pela técnica da hematoxilina-eosina (HE). Secções selecionadas de fígado e encéfalo foram coradas pela técnica do ácido periódico de Schiff (PAS). Fragmentos de córtex cerebral foram submetidos ao teste imuno-histoquímico utilizando anticorpo contra a proteína ácida glial fibrilar (GFAP) e ao antígeno S-100, empregando-se o método de streptavidina-biotina ligada à peroxidase (diluição: GFAP 1:500, DakoCytomation, CA; S-100 1:200, DakoCytomation). 0 cromógeno utilizado foi vermelho (VECTOR®NovaRED) e o contra corante, hematoxilina de Harris.

\section{Sinais clínicos}

\section{RESULTADOS}

A evolução clínica observada na intoxicação experimental por Trema micrantha e as doses utilizadas no experimento estão sintetizadas no Quadro 1. Sinais clínicos da intoxicação foram observados em 3 animais (Equinos 1, 2 e 
Quadro 1. Evolução do quadro clínico e doses utilizadas na intoxicação experimental por Trema micrantha

\begin{tabular}{ccccc}
\hline Equino & $\begin{array}{c}\text { Dose } \\
(\mathrm{g} / \mathrm{kg})\end{array}$ & $\begin{array}{c}\text { Início dos sinais } \\
\text { clínicos (horas) }\end{array}$ & $\begin{array}{c}\text { Evolução clínica } \\
\text { (horas) }\end{array}$ & Desfecho \\
\hline 1 & 30 & 18 & 61 & Morte \\
2 & 25 & 96 & 41 & Morte \\
3 & 20 & 95 & 22 & Morte \\
$4^{\mathrm{a}}$ & 15 & Sem sinais & - & Não adoeceu \\
$4^{\mathrm{b}}$ & 25 & Sem sinais & - & Não adoeceu \\
\hline
\end{tabular}

a Primeira dose administrada a este equino.

${ }^{\text {b }}$ Segunda dose administrada a este equino 30 dias após a primeira.

3). Todos os animais que apresentaram sinais clínicos evoluíram para a morte. A menor dose que causou morte dos animais foi de $20 \mathrm{~g} / \mathrm{kg}$ (Equino 3). 0 Equino 4 que recebeu $15 \mathrm{~g} / \mathrm{kg}$ de folhas frescas da planta e $25 \mathrm{~g} / \mathrm{kg} 30$ dias após a primeira dosagem, não adoeceu. Os primeiros sinais clínicos foram observados entre 18 e 96 horas após o consumo das folhas de T. micrantha. A evolução clínica variou de 22 a 61 horas. Os sinais clínicos apresentados pelos animais eram caracterizados, inicialmente, por apatia acompanhada de evacuação de fezes contendo muco e, por vezes, estrias de sangue. Os sinais clínicos evoluíram para dificuldade em se levantar, desequilíbrio e arrastamento das pinças dos membros torácicos em marcha, icterícia e disfagia, que era evidenciada pela presença de feno mastigado acumulado nos vestíbulos orais (bochechas) e no chão da baia. Posteriormente os equinos apresentavam desequilíbrio ao permanecer em estação, tremores de cabeça, ptose labial e apoiavam a cabeça com o queixo no chão, quando em decúbito esternal. 0 Equino 2 apresentou agressividade nesse estágio, tentando escoicear e morder quando manipulado. Por fim, os animais apresentavam incapacidade de permanecer em estação e até mesmo em decúbito esternal, adotando então decúbito lateral, apresentavam trismo, movimentos de pedalagem e coma seguido de morte.

\section{Análises clínicas}

Os resultados da mensuração da atividade enzimática de GGT e dos níveis séricos de glicose e amônia estão representados nas Figuras 1, 2 e 3. Elevações acima dos valores de referência de atividade sérica de GGT (4-44 UI/L) foram constatadas nos Equinos 1, 2 e 3, respectivamente em 48, 120 e 72 horas após o consumo das folhas de T. micrantha. Nos Equinos 1 e 2, os valores de atividade sérica dessa enzima apresentaram aumento até a morte e, no Equino 3, houve um pico da atividade enzimática em 72 horas após o consumo da planta e diminuição dos valores nas 48 horas seguintes. Nos Equinos 1, 2 e 3, os valores de glicemia atingiram níveis inferiores ao limite mínimo de referência $(75 \mathrm{mg} / \mathrm{dL})$ a partir de $24-48$ horas antes da morte. Os valores de amônia apresentaram níveis superiores aos de referência $(13-110 \mu \mathrm{g} / \mathrm{dL})$ nos três equinos afetados, a partir das primeiras 24 horas após o consumo da planta e continuaram em elevação até o momento da morte. Não houve alteração em nenhum dos três parâmetros no Equino 4, quando recebeu dosagem inicial de $15 \mathrm{~g} / \mathrm{kg}$, nem quando foi submetido à dose de $25 \mathrm{~g} / \mathrm{kg}$.
Atividade enzimática de GGT

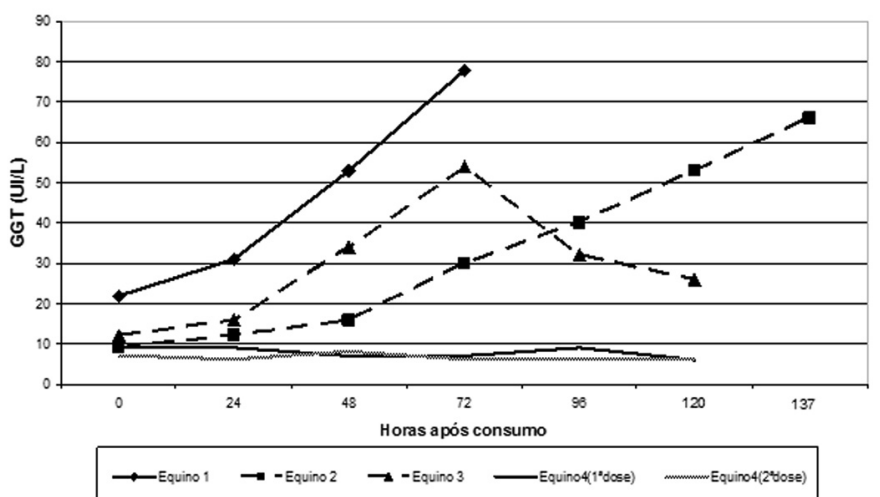

Fig.1. Resultados da mensuração da atividade enzimática de GGT em relação ao tempo após o consumo das folhas de Trema micrantha.

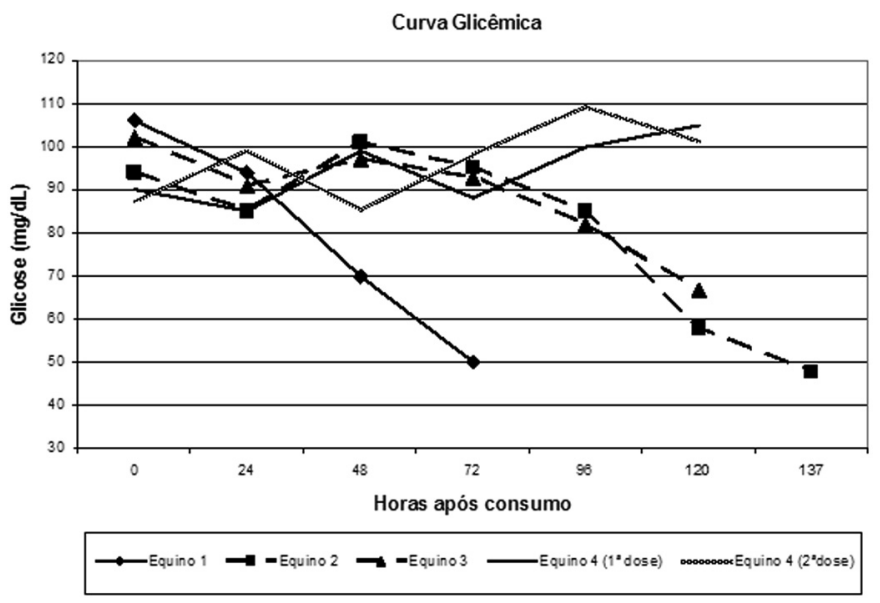

Fig.2. Resultados da mensuração da glicemia em relação ao tempo após o consumo das folhas de Trema micrantha.

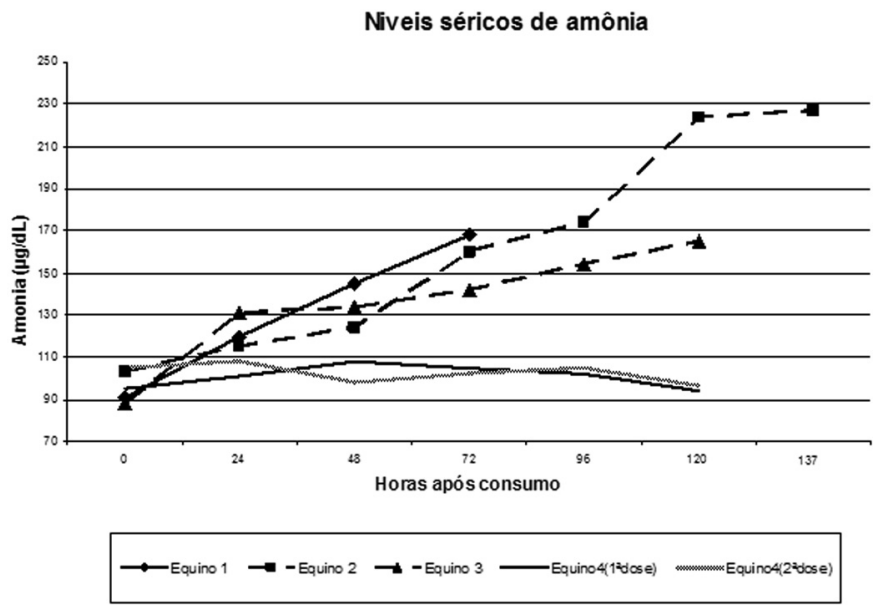

Fig.3. Níveis séricos de amônia em relação ao tempo após o consumo das folhas de Trema micrantha.

\section{Achados de necropsia}

As alterações macroscópicas observadas durante a necropsia foram semelhantes nos equinos afetados e caracterizadas por acentuação do padrão lobular no fígado, notada nas superfícies capsular e de corte e caracterizada por áreas vermelho-escuras entremeadas por áreas mais claras (Fig.4). No encéfalo dos três equinos, após serem fixados e secciona- 


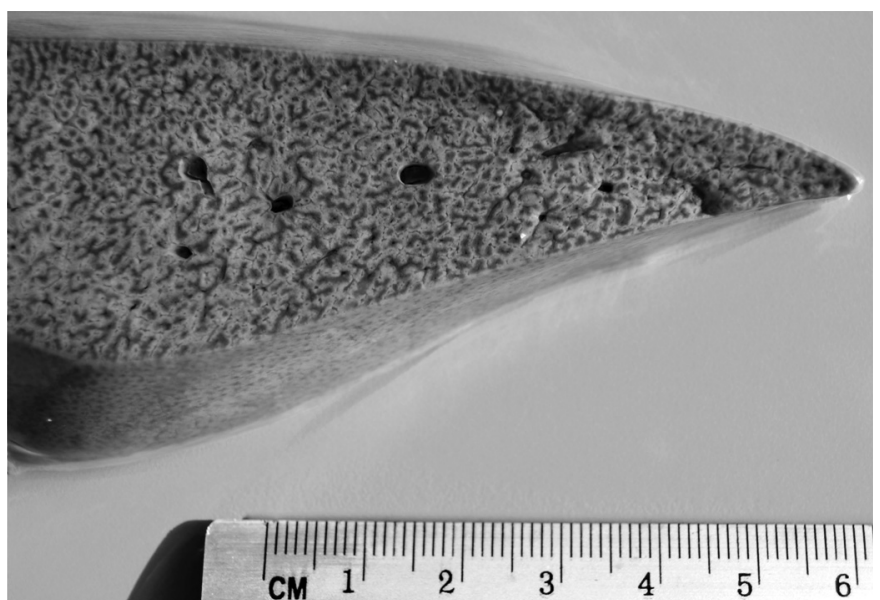

Fig.4. Fígado. Superfície de corte de fígado mostrando acentuação do padrão lobular, na intoxicação experimental por Trema micrantha. (Equino 1).

dos, foram observadas áreas amareladas e brilhantes, focalmente extensas, na superfície de corte, melhor visualizadas na substância branca e evidenciadas principalmente no cerebelo (Fig.5). No tecido subcutâneo, havia petéquias discretas. As glândulas tireóides e adrenais apresentavam hemorragia difusa. No reto, as fezes estavam secas e envoltas por grande quantidade de muco. No Equino 2, foram observadas petéquias e equimoses difusamente distribuídas no mesentério e conteúdo sanguinolento no lúmen do intestino delgado.

\section{Achados microscópicos e imuno-histoquímicos}

Os achados microscópicos dos equinos experimentalmente intoxicados foram observados principalmente no fígado e encéfalo. No fígado do Equino 1, havia necrose de coagulação predominantemente centrolobular acentuada com picnose, cariólise, cariorrexia e aumento da eosinofi-

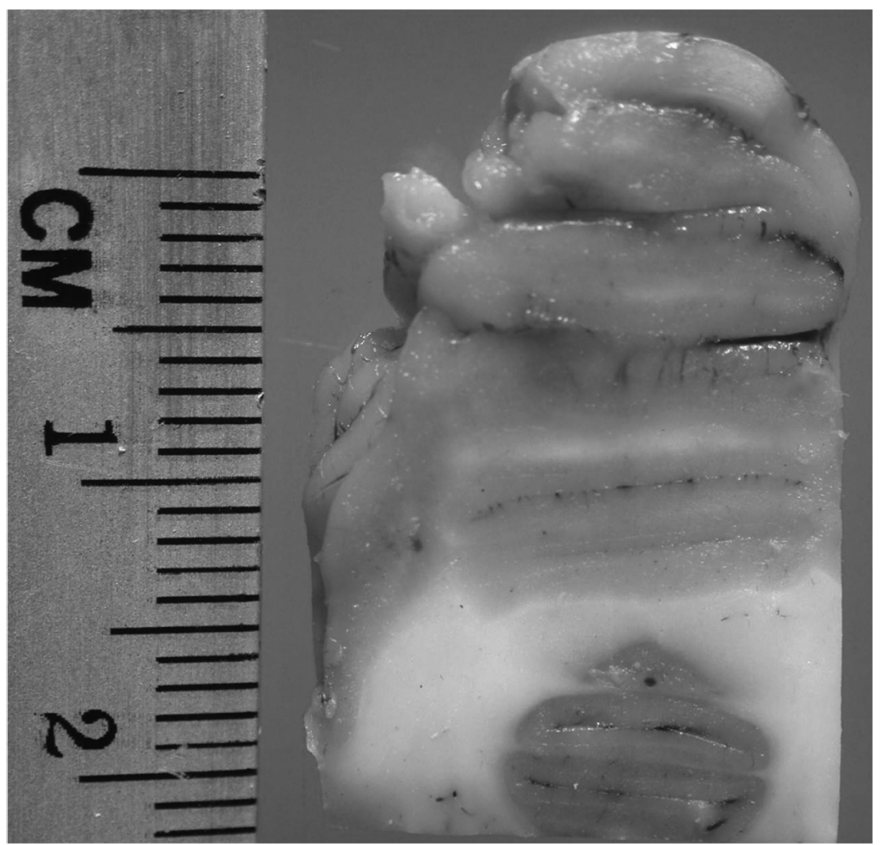

Fig.5. Superfície de corte do cerebelo mostrando área focal amarelada, na intoxicação experimental por Trema micrantha em equinos. lia citoplasmática, além de numerosos corpúsculos apoptóticos (Fig.6). No Equino 2, o fígado apresentava necrose massiva de hepatócitos, hemorragia difusa e acentuada proliferação de células de ductos biliares. No fígado do Equino 3, havia vaculolização difusa e acentuada do citoplasma de hepatócitos, necrose centrolobular com escassos restos nucleares, infiltrado de macrófagos acentuado nessa região e corpúsculos apoptóticos. As alterações no encéfalo dos três equinos eram semelhantes, porém menos evidentes no encéfalo do Equino 1. Foram visualizados, na substância cinzenta do encéfalo, principalmente no córtex cerebral, moderado número de astrócitos Alzheimer tipo II, caracterizados por apresentarem núcleos tumefeitos e cromatina dispersa, muitas vezes formando grupos de duas ou mais células (Fig.7a). Esses astrócitos possuíam marcação fraca ou ausente quando submetidos à imuno-histoquímica anti-GFAP e positiva na imuno-histoquímica anti-S100. Hemorragia perivascular discreta e edema perivascular com extravasamento de glóbulos hialinos, melhor visualizados na coloração de PAS, foram constatados difusamente distribuídos no encéfalo dos três equinos (Fig.7b).

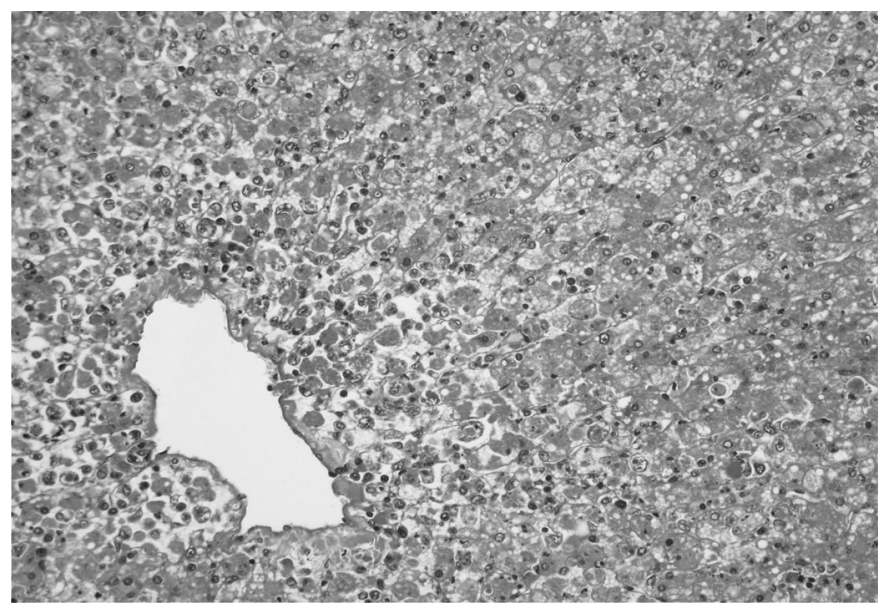

Fig.6. Necrose de coagulação no fígado, predominantemente centrolobular acentuada com picnose, cariólise, cariorrexia, aumento da eosinofilia citoplasmática, corpúsculos apoptóticos e vacuolizaçao de hepatócitos adjacentes, na intoxicação experimental por Trema micrantha (Equino 1). HE, obj.40x.

\section{DISCUSSÃO E CONCLUSÕES}

O quadro clínico-patológico observado na experimentação foi característico de insuficiência hepática aguda e semelhante ao observado nos equinos naturalmente intoxicados (Bandarra et al. 2010; Bandarra, dados não publicados). Todos os animais do presente trabalho consumiram a planta espontaneamente e todas as doses fornecidas foram consumidas em um período inferior a 24 horas, que caracteriza a planta como palatável para a espécie. A dose letal mínima de folhas de Trema micrantha estabelecida nesse experimento foi de $20 \mathrm{~g} / \mathrm{kg}$. 0 equino que recebeu uma dose de $15 \mathrm{~g} / \mathrm{kg}$ não apresentou alterações clínicas ou bioquímicas. Este mesmo equino recebeu uma segunda dose superior à dose tóxica estabelecida no experimento, trinta dias após a primeira dose, e ainda assim não desenvolveu alterações clínicas ou bioquímicas. É possível que esse equino tenha 

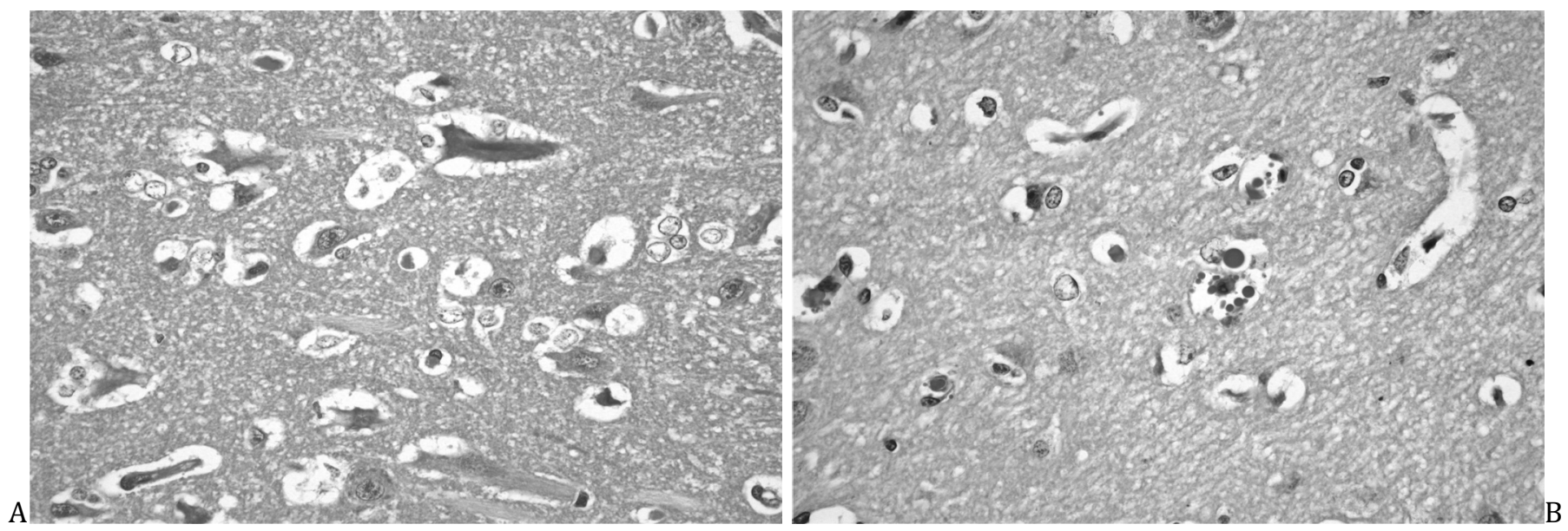

Fig.7. Córtex cerebral, na intoxicação experimental por Trema micrantha em equinos. (A) Astrócitos tumefeitos com cromatina dispersa característicos de astrócitos Alzheimer tipo II. HE, obj.20x. (B) Extravasamento perivascular de glóbulos de proteína. PAS, obj.20x.

desenvolvido tolerância com a administração prévia de uma dose subletal. Resultados semelhantes foram observados com doses progressivas, a partir de uma dose subletal de larvas de Perreyia flavipes em ovinos (Raymundo 2008) e podem ser devidos ao aumento da capacidade de detoxificação do hepatócito, relacionado à hipertrofia do retículo endoplasmático e indução do sistema de oxidases de função mista (Slauson \& Cooper 1990).

Os achados macroscópicos e histológicos observados nos animais desse experimento foram compatíveis com intoxicação por plantas hepatotóxicas de curso agudo. No Brasil, casos esporádicos de hepatotoxicidade em equinos têm também sido associados com o consumo de Senecio brasiliensis (Gava \& Barros 1997), Crotalaria retusa (Nobre et al. 2004) e Brachiaria humidicola (Barbosa et al. 2006). Entretanto, nenhuma dessas plantas tem sido associada com necrose hepática aguda nessa espécie. Por outro lado, muitas outras plantas podem causar necrose hepática aguda em herbívoros no Brasil e devem ser consideradas como diagnóstico diferencial, pois é possível que também se apresentem tóxicas para equinos. Portanto, no diagnóstico diferencial devem ser incluídas intoxicações por Cestrum corymbosum var. hirsutum, Cestrum intermedium, Cestrum laevigatum, Cestrum parqui, Crotalaria retusa, Dodonea viscosa, Myoporum laetum, Sessea brasiliensis, Vernonia molissima, Vernonia rubricaulis e Xanthium cavanillesii (Tokarnia et al. 2002, Riet-Correa \& Méndez 2007).

Degeneração e necrose coagulativa centrolobular são achados particularmente comuns em insultos hepáticos e, provavelmente, devidos a particularidades da circulação sanguínea e atividade enzimática das oxidases de função mista. Os hepatócitos da região centrolobular recebem menos oxigenação por estarem mais distantes da região porta, onde o sangue é mais oxigenado. A atividade enzimática das oxidases de função mista na região centrolobular é relativamente maior, o que predispõe a formação de metabólicos intermediários tóxicos (Cullen 2007). Hemorragias podem ocorrer secundariamente ao dano hepático devido ao consumo excessivo dos fatores de coagulação nos insultos necróticos, assim como pela incapacidade do órgão sintetizar fatores de coagulação e plaquetas (Stalker \& Hayes 2007).
As lesões neurológicas encontradas foram provavelmente decorrentes da encefalopatia hepática e associadas com a ação de neurotoxinas. A amônia, que nos casos do presente trabalho mostrou-se elevada, tem sido descrita como um fator importante neste contexto (Summers et al. 1995, Zachary 2007). No entanto, outros fenômenos, como alterações em neurotransmissores, permeabilidade da barreira hematoencefálica e metabolismo energético, também tem sido apontados como importantes para o desenvolvimento de encefalopatia hepática (Häussinger et al. 2002). Alguns destes fatores puderam ser observados nos casos aqui apresentados, como hipoglicemia e alterações na barreira hematoencefálica.

A amônia é produzida no trato gastrointestinal pela degradação bacteriana de alimentos protéicos. Em animais saudáveis é detoxificada no fígado e convertida em ureia que é excretada na urina. Com a perda de um ciclo efetivo de ureia, o tecido nervoso metaboliza a amônia através de enzimas astrocíticas à glutamina, uma substância neurotóxica que tem sido associada com as alterações degenerativas nos astrócitos e edema cerebral, semelhantes ao descrito nos equinos deste estudo, denominados astrócitos de Alzheimer tipo II (Brusilow 1986). Tipicamente estas células tinham marcação imuno-histoquímica positiva para o antígeno S-100 e marcação fraca ou ausente para GFAP. Estes achados na encefalopatia hepática têm sido relacionados a uma perda seletiva nos filamentos GFAP (Summers et al. 1995, Zachary 2007). Astrócitos degenerados Alzheimer tipo II, edema cerebral e degeneração neuronal têm sido descritos em casos de encefalopatia hepática (Häussinger et al. 2002, Cullen 2007, Norenberg et al. 2009).

As análises bioquímicas realizadas revelaram que os animais intoxicados tiveram aumento da atividade sérica de GGT e dos níveis de amônia, assim como diminuição da glicemia. 0 aumento da atividade enzimática de GGT e a diminuição dos níveis séricos de glicose são consequências esperadas de insuficiência hepática (Stalker \& Hayes 2007). Apesar de um efeito hipoglicêmico de T. micrantha ter sido demonstrado em ratos (Schoenfelder et al. 2006), o mecanismo pelo qual isto ocorre não foi elucidado. Em casos de necrose hepática zonal, os hepatócitos remanescentes po- 
dem se tornar insuficientes para manter a glicemia normal (Stalker \& Hayes 2007). Hipoglicemia foi relatada também nas intoxicações experimentais por T. micrantha em caprinos (Traverso et al. 2002) e bovinos (Traverso et al. 2004) e por Dodonea viscosa (Cattani et al. 2004) e Xanthium cavalinesi (Colodel et al. 2000) em bovinos. Nestes trabalhos a hipoglicemia foi relacionada com as lesões e sinais neurológicos observados.

A espécie equina se mostrou mais sensível à intoxicação por Trema micrantha que as demais espécies estudadas anteriormente (Traverso \& Driemeier 2000, Traverso et al. 2002, 2004). A alta sensibilidade dessa espécie aliada à palatabilidade e ampla distribuição da planta reforçam a importância de T. micrantha como causa de intoxicações acidentais em equinos.

Agradecimentos.- Aos colegas de pós-graduação e estagiários do Setor de Patologia Veterinária da Universidade Federal do Rio Grande do Sul, pela ajuda. À Coordenação de Aperfeiçoamento de Pessoal de Nível Superior (CAPES) e ao Conselho Nacional de Desenvolvimento Científico e Tecnológico (CNPq), pelo apoio financeiro.

\section{REFERÊNCIAS}

Bandarra P.M., Pavarini S.P., Raymundo D.L., Corrêa A.M.R., Pedroso P.M.O \& Driemeier D. 2010. Trema micrantha toxicity in horses in Brazil. Equine Vet. J. 42:456-459.

Brusilow S.W. 1986. Hepatic encephalopathy. N. Engl. J. Med. 314:786-787.

Barbosa J.D., Oliveira C.M.C., Tokarnia C.H. \& Peixoto P.V. 2006. Fotossensibilização hepatógena em equinos pela ingestão de Brachiaria humidicola (Gramineae) no Estado do Pará. Pesq. Vet. Bras. 26:147-153.

Castellani E.D. \& Aguiar I.B. 1998. Preliminary conditions for germination of Trema micrantha (L.) Blume seeds. Revta Bras. Eng. Agric. Ambien. 2:80-83.

Cattani C.S., Colodel E.M., Traverso S.D., Correa A.M.R. \& Driemeier D. 2004. Intoxicação experimental por Dodonea viscosa (Salpindaceae) em bovinos. Pesq. Vet. Bras. 24(1):31-34.

Colodel E.M., Driemeier D. \& Pilati C. 2000. Intoxicação experimental pelos frutos de Xanthium cavanillesii (Asteraceae) em bovinos. Pesq. Vet. Bras. 20:31-38.

Cullen J.M. 2007. Liver, biliary system, and exocrine pancreas, p.393-461. In: McGavin M.D. \& Zachary J.F. (Eds), Pathologic Basis of Veterinary Disease. $4^{\text {th }}$ ed. Mosby Elsevier, St Louis. 1476p.

Gava A. \& Barros C.S.L. 1997. Senecio spp. poisoning of horses in southern Brazil. Pesq. Vet. Bras.17:36-40.

Häussinger D., Schliess F. \& Kircheis G. 2002. Pathogenesis of hepatic encephalopathy. J. Gastroenterol. Hepatol. 17:256-259.

Hill B.D., Wills L.D. \& Dowling R.M. 1985. Suspected poisoning of horses by Trema aspera (poison peach). Aust. Vet. J. 6:107-108.

Kissmann K.G. 2000. Plantas Infestantes e Nocivas. $2^{\text {nd }}$ ed. BASF, São Paulo, p.643-644.

Lorenzi H. 2008. Árvores Brasileiras: manual de identificação e cultivo de plantas arbóreas do Brasil. Vol.1. $5^{\text {th }} \mathrm{ed}$. Instituto Plantarum de Estudos da Flora Ltda, Nova Odessa, p.90.

Mckenzie R.A., Green P.E., Thornton A.M., Chung Y.S. \& Mackenzie A.R., Cybinski D.H. \& St. George T.D. 1985. Diseases of deer in southeastern Queensland. Aust. Vet. J. 62:424.

Mulhearn C.R. 1942. Poison peach (Trema aspera): a plant poisonous to stock. Aust. Vet. J. 18:68-72.
Naftalin L., Sexton M., Whitaker J.F. \& Tracey D. 1969. A routine procedure for estimating serum gamma-glutamyltranspeptidase activity. Clin. Chim. Acta 26:293-296.

Nobre V.M.T., Riet-Correa F., Filho J.M.B., Dantas A.F.M., Tabosa I.M. \& Vasconcelos J.S. 2004. Intoxicação por Crotalaria retusa (Fabaceae) em eqüídeos no semi-árido da Paraíba. Pesq. Vet. Bras. 24:132-143.

Norenberg M.D., Rama Rao K.V. \& Jayakumar A.R. 2009. Signaling factors in the mechanism of ammonia neurotoxicity. Metabol. Brain Dis. 24:103117.

Oelrichs P.B. 1968. Isolation and purification of trema toxin from Trema aspera. Phytochem. 7:1691-1693.

Pio-Correa M. 1984. Dicionário das Plantas Úteis do Brasil e das Exóticas Cultivadas. Vol.II. Ministério da Agricultura, Brasília, p.439.

Raymundo D.L. 2008. Intoxicação espontânea por larvas de Perreyia flavipes (Pergidae) em ovinos e bovinos e intoxicação experimental em ovinos e coelhos. Dissertação de Mestrado em Patologia Animal, Faculdade de Veterinária, Universidade Federal do Rio Grande do Sul, Porto Alegre, RS. 55p.

Riet-Correa F. \& Méndez M.C. 2007. Intoxicações por plantas e micotoxinas, p.99-221. In: Riet-Correa F., Schild A.L., Lemos R.A.A. \& Borges J.R.J. (Eds), Doenças de Ruminantes e Eqüídeos. $3^{a}$ ed. Pallotti, Santa Maria. $694 \mathrm{p}$.

Schoenfelder T., Cirimbelli T.M. \& Citadini-Zanette V. 2006. Acute effect of Trema micrantha (Ulmaceae) on serum glucose levels in normal and diabetic rats. J. Ethnopharmacol. 107:456-459.

Slauson D.O. \& Cooper B.J. 1990. Mechanisms of Diseases. $2^{\text {nd }}$ ed. Williams and Wilkins, Baltimore, USA. 540p.

Stalker M.J. \& Hayes M.A. 2007. Liver and biliary system, p.297-381. In: Maxie M.G. (Ed.), Jubb, Kennedy, and Palmer's Pathology of Domestic Animals, Vol.2. $5^{\text {th }}$ ed. Elsevier, St Louis.

Summers B.A., Cummings J.F. \& de Lahunta A. 1995. Veterinary Neuropathology. Mosby, St Louis, Missouri. 527p.

Tokarnia C.H., Döbereiner J. \& Peixoto P.V. 2002. Poisonous plants affecting livestock in Brazil. Toxicon 40:1635-1660.

Traverso S.D., Corrêa A.M.R., Schmitz M., Colodel E.M. \& Driemeier D. 2004. Intoxicação experimental por Trema micrantha (Ulmaceae) em bovinos. Pesq. Vet. Bras. 24:211-216.

Traverso S.D. \& Driemeier D. 2000. Experimental Trema micrantha (Ulmaceae) poisoning in rabbits. Vet. Human Toxicol. 42:301-302.

Traverso S.D., Correa A.M.R., Pescador C.A., Colodel E.M., Cruz C.E.F. \& Driemeier D. 2002. Intoxicação experimental por Trema micrantha (Ulmaceae) em caprinos. Pesq. Vet. Bras. 22:141-147.

Traverso S.D., Colodel E.M., Loretti A.P., Corrêa A.M.R. \& Driemeier D. 2003. Intoxicação natural por Trema micrantha em caprinos. Ciência Rural 33:133-136.

Traverso S.D., Zlotowski P., Germer M., Cruz C.E.F. \& Driemeier D. 2005. Spontaneous poisoning by Trema micrantha (Ulmaceae) in goats. Acta Sci. Vet. 33:207-210.

Trinder P. 1969. Determination of glucose in blood using glucose oxidase with an alternative oxygen acceptor. Ann. Clin. Biochem. 6:24-27.

Trueman K.F. \& Powell M.W. 1991. Suspected poisoning of camels by Trema tomentosa (poison peach). Aust. Vet. J. 68:213-214.

Vasquez Y.C. 1998. Trema micrantha (L.) Blume (Ulmaceae): a promising neotropical tree for site amelioration of deforested land. Agrofor. Syst. 40:97-104.

Verdouw H., Van Echted C.J.A. \& Dekkers E.M.J. 1978. Ammonia determination based on indophenol formation with sodium salicylate. Water Res. 12:99-402.

Zachary J.F. 2007. Nervous system, p.833-971. In: McGavin M.D. \& Zachary J.F. (Eds), Pathologic Basis of Veterinary Disease. $4^{\text {th }}$ ed. Mosby Elsevier, St Louis. 